\title{
A partial least squares approach to digital finance adoption
}

\author{
Niyati Jain ${ }^{1} \cdot$ T. V. Raman ${ }^{2}$
}

Received: 27 July 2021 / Revised: 11 November 2021 / Accepted: 15 November 2021 / Published online: 25 November 2021

(c) The Author(s), under exclusive licence to Springer Nature Limited 2021

\begin{abstract}
In present times, the adoption and adaption of technology have become empirical. This paper helps in determining the factors of perceived risk and perceived benefits in order to understand the willingness or hesitance of people to adopt digital finance. An attempt is made to study the influence of perceived risk and benefit as the determinants of digital finance adoption. The data were collected from individuals of Northern India through a structured questionnaire. The study collected data from 411 respondents through a structured questionnaire. Partial Least Square Structural Equation Modelling has been adopted to analyze the data through SmartPLSv2. For better understanding, perceived risk constituted three constructs-Security risk, financial risk and performance risk, and perceived benefit included seamless transaction, economic benefit and convenience. The research concluded that both perceived risk and benefits influence the adoption of digital finance. Perceived benefit has more impact on digital finance adoption than perceived risk. The findings of the paper are beneficial for digital finance service providers and marketers to enhance the awareness and advantages of digital finance according to the needs of consumers. The present study adds value to the existing literature on the relationship between perceived risk, perceived benefit and adoption of digital finance.
\end{abstract}

Keywords Perceived risk $\cdot$ Perceived benefit $\cdot$ Digital finance adoption

\section{Introduction}

Information technology has led to a great amount of development and expansion in the field of Finance. Digital Finance has gained importance in the past few years and is attracting the attention of researchers and industrialists. In the era of industrial and economic growth, adoption and adaption of technology have become of paramount importance (Fu 2014). The availability of financial services online was first referred to as financial technology in the 1990s, whereas, in the 2000s, it was referred to as digital finance or e-finance (Razzaque et al. 2020). Evolution of Fintech from automated teller machines, credit cards to mobiles and app services have been remarkable in the financial sector (Gomber et al. 2017).

Niyati Jain

niyati96@gmail.com

1 Amity College of Commerce and Finance, Amity University, Noida, Uttar Pradesh, India

2 Amity Busines School, Amity University, Noida, Uttar Pradesh, India
Demonetisation in India in 2016 led to the acceleration of the adoption of digital payments due to the low circulation of cash in the economy (Frakman 2020). The penetration of digitization in the financial industry was further backed by the Covid-19 (Arner et al. 2020). The 2008 crisis was a financial crisis, whereas the Covid-19 pandemic is a health crisis that impacts the financial sector and, therefore, the economy. Digital financial services, mainly digital wallets, can quickly and accurately send funds to those in need (Arner et al. 2020). The covid-19 pandemic has brought attention to digital financial services due to the increasing pressure of social distancing (Agur et al. 2020). Fu and Mishra (2020) documented the spurt of digitization in the financial sector by considering the early impact of Covid-19 spread on fintech adoption globally. Therefore, the study has included the adoption behaviour of individuals post the early stage of covid-19 in digital finance.

In the present times, consumers require a convenient and cost-effective way to access financial services. As the young generation is more inclined to use technology, including the internet and digital platforms, consumers are moving towards digital finance. However, consumers are still reluctant to disclose their personal information as well as 
financial information on online platforms. According to Agarwal et al. (2017), two factors will determine the successful implementation of digitalization. First, the adoption of digital solutions by the low-income segment group, which are governed by access and usage of mobiles, credit, banking services and digital literacy. Second, the willingness of users to adopt digital finance continuously for financial transactions, given awareness of all the options available. One of the key components of determining the country's growth is the acceptance and adoption of technology by its citizens. With the Innovation and advancement in the technology sector, finance technology has become the new normal.

There has been a significant increase in the per cent of adoption of Fintech by consumers from 16\% in 2015, 33\% in 2017, to 64\% in 2019. Awareness of Fintech is relatively high among the consumers, including the non-adopters. Fintech has evolved in a manner where consumer expectations have become significant (Ernest \&Young, 2019). Although financial technology has attracted a great number of users, the continuance usage of digital finance is still a question. Some users are doubtful in continuing the use of digital finance due to considerable risks. Users want to determine if the usage of digital financial services will be more beneficial or will it cause more risks. A consumer will only adopt digital finance if its benefits outweigh the risks involved. In order to determine the continuous usage of digital finance, it is empirical to identify the factors that will boost the use of digital finance. According to McKinsey Global Institute (MGI) report, mobile phones will facilitate as a gamechanger in digital finance. The cost of financial services can be reduced up to $80-90 \%$ with the help of mobile payments (Thomas and Hedrick-Wong 2019).

In order to enhance and improve the understanding of behaviour behind the adoption of digital finance, it is empirical to investigate the determinants that influence the adoption of new technology in order to understand the technological changes (Bergek et al. 2008). The following research questions have been framed:

1. Does the user's perception of risk influence the adoption of digital finance?

2. Does the user's perception of benefit influence the adoption of digital finance?

3. What factors specifically influence the user's intention to adopt digital finance?

Earlier studies have recognized the factors of behavioural intention in the adoption of various financial services (Meyliana et al. 2019; Yang et al. 2015; Gerlach and Lutz 2019; Tiong 2020). However, very few studies include both factors, i.e., perceived benefits and perceived risks, to determine the adoption of digital finance. There are a limited number of studies that explores the adoption of digital finance.
Therefore, this study also focuses on overcoming this research gap. This paper will focus on bridging the research gaps, where the impact of both perceived benefits (positives) and perceived risks (negatives) will be determined on the adoption of digital finance.

The following are the additions to the literature that this study intends to make. The research aims to broaden the scope of the adoption decision by explicitly incorporating both positive (perceived benefit) and negative (perceived risk) elements at the same time by addressing early stage covid-19 impact in adoption behaviour as the data was collected after the early stage of covid-19 pandemic. Second, using the net valence framework, this research can assist practitioners to better understand benefit and risk perceptions, which can be utilized to build benefit-increasing and risk-reducing methods to boost digital finance adoption. Finally, our findings give Fintech companies useful insight into which issues should be addressed or avoided when providing digital financial services to their customers. The remaining part of the paper is followed by the literature review, hypothesis formulation, research methodology, results, analysis and conclusion.

\section{Literature review and hypotheses formulation}

\section{Literature review}

\section{Risk-benefit framework}

Judgements of Risk and Benefits are inversely related. The higher the value of perceived risk, the lower is the value of the perceived benefit and vice versa (Alhakami and Slovic 1994). While making a decision, a consumer is faced with uncertainties and hesitance (Kim et al. 2008). Therefore, risk perception is an important factor in analyzing adoption behaviour. Perceived benefit also has a significant role in analyzing adoption behaviour (Wilkie and Pessemier 1973). The researcher emphasized that the consumers will have both negative and positive outlooks while considering adopting new technology. Thus, (Peter \& Tarpey, 1975) postulated a net-valence framework. The framework assumes that consumers will only adopt a new service/ product when it is most beneficial or desirable. The present research combines TRA theory with the net-valence framework. The Theory of Reasoned Action (TRA) theory postulates that people can execute their behaviour as they have reasons or opportunities to control their behaviour (Ajzen and Fishbein 1977; Staats 2004). According to the theory, individuals could also govern their behaviour if given specific causes or incentives (Staats 2004). Perception is vital in determining an individual's intention to embrace or use digital financial 
services. Risks and advantages, in particular, may be considered behavioural elements in defining a person's behaviour intention (Jurison 1995). There are few studies that have studied the factors or the benefit-risk framework that have an impact on the adoption of E-finance services (Ryu 2018; Abramova and Böhme 2016; Liu et al. 2012; Lee 2009). Every study has explained perceived risk and perceived benefits as multidimensional factors.

Ryu (2018) studied willingness and hesitance of users in the adoption of financial technology. It explained perceived benefits by categorizing it into three factors-economic benefit, seamless transaction and convenience. Perceived risks were classified into four factors-legal risk, financial risk, security risk and operational risk. Further, the study also included how user type can impact the adoption of financial technology. The research highlighted that legal risk is a dominant factor in influencing the continuous intention of Fintech. While convenience is a consistent factor that plays a significant role in influencing perceived benefit. It was also concluded that differences between perceived benefit and risk influence early and late adopters. Abramova and Böhme (2016) researched the determinants and drivers for the adoption of Bitcoin. The researchers integrated perceived risks and perceived benefits with the technology acceptance model. The factors of perceived benefits included-seamless transaction, security and control, and decentralization and components of perceived risks included-financial losses, legal risk, operational risk, and adoption risk.

Liu et al. (2012) explained three variables, i.e., perceived benefits, perceived risks and the perceived value that influence the adoption of mobile payment technology. Perceived risk constituted factors, namely -financial risk, privacy risk and psychological risk, whereas perceived benefits and perceived value were taken as single dimension factors. The study emphasized that financial risk is the most influential variable of perceived risk to influence the adoption of mobile payments. Lee (2009) proposed an integrated model to explain the user's intention to adopt internet banking. The researcher studied perceived risk and benefit and integrated them with both the technology acceptance model and the theory of planned behaviour. Perceived risk consisted of five factors-financial, security/privacy, performance, social and time risk, while perceived benefit was taken as a single construct. Security Risk has been revealed as the most important indicator to influence the adoption of online banking, whereas the perceived benefit has been concluded to be the most positive influencing inhibitor on intention to use online banking.

\section{Perceived risk and its determinants}

Perceived risk refers to negative outcomes or uncertainty for the usage of any service or product (Featherman and Pavlou
2003). It has been outlined as "a combination of uncertainty plus seriousness of outcome involved" (Bauer 1967). There are a few studies that examined perceived risk to adopt e-finance or e-services (Alalwan et al. 2018; Martins et al. 2014; Safeena et al. 2011).

Fernando (2019) researched the impact of trust and risk on the adoption of fintech services. It has been concluded by the researcher that trust positively influences the adoption of Fintech. In contrast, the risk does not impact the adoption of Fintech, which further does not influence the attitude of users. Yang et al. (2015) discussed that uncertainties about financial transactions and risk towards them have caused resistance among consumers to adopt online payments. The research explored perceived risk and trust as the two major contributors that could impact online payment adoption. The researcher bifurcated perceived risk into systematic perceived risk and transactional perceived risk. It was concluded that systematic risk has a positive impact on trust, whereas transactional risk negatively influences trust. Im et al. (2008) explored four moderating variables, i.e., perceived risk, user experience, gender and technology type, to examine their impact on behavioural intention. The researcher concluded that all four variables were significant as moderating factors.

Further, perceived risks have been categorized into six items, i.e., financial risk, performance risk, safety risk, social risk, psychological risk and time risk. Cunningham (1967). While transferring these risks to the current study and based on the literature review, three types of perceived risks have been developed-1. Financial risk, 2. Security Risk and 3. Performance Risk. Financial Risk refers to financial loss due to financial transaction error or misuse of the bank account (Kuisma et al. 2007; Forsythe et al. 2006). Security Risk is defined as the monetary loss that can be caused due to fraud or hacking the protection or security of the financial transaction. In addition to fraud and hacking, consumers are also concerned about identity theft and privacy intrusions (Lee 2009). Performance Risk refers to any glitch in the functioning of the servers that cause a delay in financial transactions and lead to financial losses (Kuisma et al. 2007).

\section{Perceived benefits and its determinants}

Perceived benefits refer to positive outcomes in reaction to threats (Chandon et al. 2000). Zhao and Bacao (2021) aimed at examining mental and technological factors that will impact the intention of consumers in adopting M-payment during the Covid-19 pandemic in China. The research highlighted that constructs like perceived benefits, social influence, performance expectancy, perceived security, and trust significantly influence users' adoption of M-payment. The study focussed on antecedents of m-payment and concluded that there existed a causal relationship between trust, social 
influence determining perceived benefits. Further, trust and effort expectancy influenced performance expectancy. Wong et al. (2021) investigated the impact of perceived benefits and harms of the Covid-19 pandemic on the well-being of the family and their connotation on sociodemographic aspects in adults. The study highlighted that the influence of both perceived benefits and harm were under control, after the two waves of Covid-19, on family well-being. The difference in Sociodemographic aspects were more in perceived benefits than harms. Okazaki and Mendez (2013) examined perceived convenience, extrinsic variables (speed, simultaneity and speed), intrinsic variables (interface design and portability) and ease of use to determine their impact on the adoption of mobile commerce. The study also included gender as the moderating factor. Ease of use and interface design motivated females more than men to adopt mobile commerce.

The study, based on the literature review, proposes three perceived benefit factors, i.e., Seamless transaction, convenience and economic benefits. Seamless transactions refer to simple and speedy transactions while avoiding the traditional financial institution (banks) by the users (Chishti 2016). Convenience is driven by easy accessibility and is defined as flexibility in time and location, which is most important for the success of mobile and online services. Kim et al. (2010). The economic benefit helps in cost-effectiveness and financial gains (Ryu 2018).

\section{Digital finance}

Digital Finance illustrates the digitalization of the finance industry. It is defined as financial services delivered via credit cards, electronic exchange systems, internet banking, home trading services, mobile payments, and online loans (Bank 2001; Li et al. 2019). Mobile phones, the internet and cards are a few ways through which financial services can be provided (Manyika et al. 2016). Digital finance comprehends not only financial products but also financial businesses, finance-related software. It further includes forms of customer communication and interaction, which is delivered by innovative financial service providers and FinTech companies (Gomber et al. 2017). To assess digital financial services, a user needs a few components-A digital platform, a retail agent and the device (CGAP 2015). Digital Finance users should have an existing bank account with sufficient balance to make a withdrawal or receive payments through mobile phones, computers or internet service (Ozili 2018).

Digital finance could be a useful instrument for getting resources to the people who need them the most swiftly and efficiently (Arner et al. 2020). Traditional crisis management objectives can now be achieved with greater potency and accuracy using digital financial technologies (Arner et al. 2016). Digital finance delivers vital technologies that can be extremely useful, but it also introduces new types of risk (Buckley et al. 2020). The digital expansion increases the danger of crime, with digital crime being the fastest-growing type of crime. People have been obligated to use digital financial services and payment networks as part of the online commercial sector due to Covid-19 (Arner et al. 2020). Digital financial services have the potential to improve the share of the people engaging in the formal financial system in less developed nations, particularly among rural areas with limited access to banking and financial services (Finau et al. 2016). FinTech enterprises and creative financial service providers supply a slew of new financial products, financial businesses, finance-related software, and unique ways of client communication and interaction under the banner of digital finance. In light of this, financial and information systems research have begun to examine these shifts and the influence of digital advancements on the financial industry (Gomber and Koch 2017).

Digital Finance has some advantages. Such as, it leads to expansion of financial services to individuals and heads to financial inclusion. Second, Digital Finance provides convenient and affordable banking services to individuals. It can help in moving from a cash-based economy to digitalized economy. Third, it helps provide a varied range of financial products to individuals, which further helps in boosting the Gross Domestic Product of the country. Fourth, the adoption of digital finance can lead to a reduction in the circulation of fake money. Other benefits include quick financial decision making, control over personal financial records and receiving or making payments in a few seconds by the users of digital finance services. Digital Finance also has some disadvantages. For Instance, the user needs to have a digital device with an internet and bank account to take advantage of digital finance. In the digital finance, data can easily be breached, which further reduces the customer's trust to adopt digital finance platforms. Another disadvantage of digital finance is that it is fee-based. Therefore, the benefits of digital finance will be high in high and medium-income earners, whereas poor and low-income earners will not be able to afford the financial services (Ozili 2018).

Featherman and Pavlou (2003) explained how e-services have been increasingly gaining popularity amongst the consumers, and so the researcher analyzed the consumers potential to adopt these e-services. The study identified that performance-based risks are a major concern, while perceived ease of use helps in reducing these risks. Therefore, it concluded that performance, financial, time and privacy risks are major risk concerns for the adoption of e-services. Gerlach et al. (2019) demonstrated prospective variables that will impact the present usage as well as future usage of adopting Fintech and digital finance solutions. The research attempted to explain behavioural intention as a dependent variable and Perceived risk (Financial risk, Security risk, 
Legal risk and Operational risk), Perceived benefits (Economic benefits, seamless transactions and convenience) as independent variables. The study also focussed on independent constructs like performance expectancy, social influence, effort expectancy, facilitating conditions, price value, hedonic motivation and habit. The study intends to determine the past and present usage behaviour with future usage behaviour of Fintech and digital finance solutions. Aisaiti et al. (2019) explored inclusive finance and analyzed perceived risk, perceived benefits and knowledge of inclusive finance. The researcher considered digital finance and social embeddedness as moderating variables for analyzing the adoption intention of inclusive finance. The researcher concluded that perceived risk has a negative influence, and perceived benefit has a positive influence on the adoption intention of inclusive finance. The study also highlighted that social embeddedness lowered the impact of perceived risk and increased the influence of perceived benefits on ordering finance. Whereas digital finance as a moderating factor supported the impact of perceived benefits on the intention to adopt Inclusive Finance. Finau et al. (2016) explored the deterrents and benefits of digital financial services in Fiji rural areas. Both perceived risk and benefits were considered while analyzing the adoption behaviour. According to the findings of (Königsheim et al. 2017), financial expertise and risk tolerance are highly connected with the likelihood of using digital financial services.

\section{Hypotheses formulation}

The significance of perceived risk has been gained in Consumer and IT literature. It has been described as a barrier in intention to adopt digital finance. Previous studies have established a negative relationship between perceived risk and IT services adoption (Abramova and Böhme 2016; Ryu 2018; Benlian and Hess 2011; Farivar and Yuan 2014; Lee 2009). Thus, the first hypothesis has been framed as:

$H_{1}$ : Perceived Risk negatively influences Digital finance adoption.

Perceived benefits have always been a motivator in IT services adoption for consumers (Kim et al. 2008; Melewar et al. 2013). Previous literature has emphasized the positive relationship of perceived benefit and IT services adoption (Abramova and Böhme 2016; Ryu 2018; Benlian and Hess 2011; Farivar and Yuan 2014; Lee 2009). Abramova and Böhme (2016) in their study established a positive relationship between perceived benefits and bitcoin usage. Hence, the second hypothesis has been framed as:

$\mathrm{H}_{2}$ : Perceived Benefit positively influences Digital finance adoption.

Three indicators of perceived risks have been identified for the adoption of digital finance-financial risk, performance risk and security risk. A positive relationship between the financial risk (Benlian and Hess 2011; Melewar et al. 2013), security risk (Lwin et al. 2007) and perceived risks (Ryu 2018). A positive relationship has also been established between performance risk and perceived risks (Lee 2009). Thus, the following hypotheses have been framed:

$\mathrm{H}_{3}$ : Financial risk is associated with perceived risk.

$\mathrm{H}_{4}$ : Security risk is associated with perceived risk.

$\mathrm{H}_{5}$ : Performance risk is associated with perceived risk.

Further, perceived benefits have also been classified into three factors, namely- convenience, seamless transactions and economic benefits. A positive relationship between convenience (Kim et al. 2010), economic benefit (Mackenzie 2015), seamless transaction (Chishti 2016) and perceived benefits have been established (Ryu, 2018). Hence, the following hypotheses have been generated for the study:

$H_{6}$ : Economic benefit is associated with perceived benefit.

$H_{7}$ : Seamless transaction is associated with perceived benefit.

$\mathrm{H}_{8}$ : Convenience is associated with perceived benefit.

\section{Research methodology}

\section{Data collection and sample design}

The study is based on a quantitative approach to identify the risks and benefits of the adoption of digital finance, so the research is entirely based on primary data. The questionnaire has been chosen as a method to collect data for geographically scattered population. (Robson and McCartan 2016). The data have been collected from Northern regions of India, including Amritsar, Jalandhar, Delhi, Noida, Ghaziabad, Faridabad, Ludhiana, Gurgaon, Ambala, Chandigarh and Panipat. Due to the ongoing pandemic, purposive sampling has been used to collect the responses via digital platforms. The minimum sample size was estimated with the help of $\mathrm{G}^{*}$ power software (Faul et al., 2009). The sample size was estimated at 159 respondents at 0.80 power with 95\% confidence level. Out of the 500 questionnaires distributed, the responses were received from 433 respondents. About 411 responses were accepted for the final analysis as the remaining respondents were excluded due to missing values and outliers. The response rate is acceptable, as suggested by (Nutty 2008). The Smart PLS 2.0 software has been used to conduct the analysis of the final data.

\section{Measurement of variables}

The proposed model consists of nine variables adapted from previous studies. The items, however, were altered according to the need of the study. The structured questionnaire was created using a five-point Likert scale, and the responses were analyzed using partial least squares-structural equation 
Table 1 Construct and their sources

\begin{tabular}{lll}
\hline Constructs & No. of Items & Source \\
\hline Perceived Risk & 3 & Kim et al. (2008) and Benlian and Hess (2011) \\
Financial Risk & 3 & Featherman and Pavlou (2003) and Lee (2009) \\
Security Risk & 3 & Featherman and Pavlou (2003) and Lee (2009) \\
Performance Risk & 3 & Featherman and Pavlou (2003) and Lee (2009) \\
Perceived Benefit & 4 & Kim et al. (2008) and Benlian and Hess (2011) \\
Economic Benefit & 3 & Featherman and Pavlou (2003) and Lee (2009) \\
Seamless Transaction & 3 & Chishti (2016) \\
Convenience & 3 & Okazaki and Mendez (2013) \\
Adoption of Digital Finance & 3 & Cheng et al. (2006) and Lee (2009) \\
\hline
\end{tabular}

modelling (PLS-SEM). The link between the variables was investigated using the smartPLSv2.0 software. PLS-SEM is a second-generation exploratory technique for determining the effect of exogenous variables on the endogenous variable (Hair et al. 2012, 2019, Reinartz et al. 2009).

The survey was influenced and composed by undertaking an extensive literature review. Perceived Risk and Perceived Benefit was inspired by Kim et al. (2008), Benlian and Hess (2011). Whereas constructs like an economic benefit, financial risk and security risk were influenced by Featherman and Pavlou (2003), Lee (2009). Other variables like performance risk (Featherman and Pavlou 2003; Lee 2009), Seamless transaction (Chishti 2016) and Convenience (Okazaki and Mendez 2013) are adapted from respective literature. The dependent variable, i.e., Adoption of digital Finance, has been influenced and adapted from the works of researchers, namely (Cheng et al. 2006; Lee 2009). Some of the independent variables included, i.e., financial risk, security risk, perceived benefit, and convenience, have together been included in the research paper (Gerlach et al. 2019). The summary has been displayed in Table 1 .

\section{Results}

\section{Demographic profile}

Table 2 summarises the demographic profile of the survey respondents. Among the respondents, 223 were males, and 188 were females. Most of the respondent's ages varied between 25 and 35 years, constituting $34.1 \%$, followed by $45-55$ years with $28 \%$. The others constituted $24.3 \%$ (35-45 years), $10.7 \%$ (55 years and above) and $2.9 \%$ (18-25 years). The majority of the respondents were either graduates or post-graduates. The respondents were asked which type of digital finance was mostly used by them. Digital Finance was bifurcated into five categories, i.e., Internet Banking, Mobile Banking, Mobile wallets, Credit cards and Debit cards. Internet banking was the most used,
Table 2 Demographic information

\begin{tabular}{lcc}
\hline Characteristics & Frequency & Percentage (\%) \\
\hline Gender & & \\
Male & 223 & 54.30 \\
Female & 188 & 45.70 \\
Age & & \\
18-25 years & 12 & 2.90 \\
25-35 years & 140 & 34.10 \\
35-45 years & 100 & 24.30 \\
45-55 years & 115 & 28.00 \\
Above 55 years & 44 & 10.70 \\
Educational Qualification & & \\
High School & 14 & 3.4 \\
Diploma & 70 & 17.00 \\
Graduate & 165 & 40.10 \\
Post-graduate & 129 & 31.4 \\
PhD & 33 & 8.00 \\
Most Digital Financial services used & & \\
Internet Banking & 118 & 28.70 \\
Mobile Banking & 117 & 28.50 \\
Mobile Wallets & 39 & 9.50 \\
Credit Cards & 38 & 9.20 \\
Debit Cards & 99 & 24.10 \\
\hline
\end{tabular}

whereas Credit cards were the least used form of digital finance by the respondents.

Further, the data were first checked for any missing values or outliers with the help of SPSSv25. The analysis of data through measurement model and structural model was done on SmartPLSv2.0. The measurement model implies the relationship between the latent variables and their consisting variables, whereas the structural model will help determine the cause and effect relationship between the dependent and independent variables. SmartPLS was chosen for its appropriateness for hypothesis testing and explaining the relationship among the variables (Chin 1998). 


\section{Measurement model}

The measurement model was first examined for multivariate normality. The web software was used to check the normality of data through multivariate kurtosis and skewness (Cain et al. 2017; Mardia 1970). The results signified that the data lacked multivariate normality as the $P<0.05$ for kurtosis and skewness. Thus, PLS-SEM was chosen for analyzing the data (Hair, Risher, Sarstedt, \& Ringle, 2019). Further, the data were checked for common method bias. According to Podsakoff et al. (2003), a single factor should not account for a variance of more than $50 \%$ for model assessment. The concern for common method bias was eliminated since its value for the present analysis was established at less than 50\%.

Three parameters of validity and reliability were chosen to assess the reflective measurement model, i.e., indicator reliability, convergent validity and discriminant validity (Coltman et al. 2008; Hair et al. 2011). The values of outer loadings were more than 0.7 , as shown in Table 3 . Therefore indicator reliability is justified. Further, the convergent validity of the model was evaluated through internal consistency
(Cronbach Alpha) (rho Alpha), Composite Reliability (CR) and Average Variance Extracted (AVE) (Barclay et al. 1995). The internal consistency was verified through the values of Cronbach Alpha and rho alpha which were all above 0.7 (Nunnally and Bernstein 1994; Henseler et al. 2015). The values of composite reliability were all higher than 0.7 , and so the data is reliable. AVE is also above the value of 0.5 (Bagozzi and Yi 1988), so the data has been approved for convergent validity.

The Discriminant Validity was verified through the values of the square root of AVE and its comparison with the intercorrelation of constructs with other measures (Fornell and Larcker 1981). The values on the diagonal in Table 4 represented the square root of AVE, and the values off-diagonal represented the inter-correlation between the constructs. Since the value of the square root of AVE was greater than the inter construct correlation, discriminant validity was proven, reasoned that (Fornell and Larcker 1981) is not adequate for determining the discriminant validity. Thus, The Discriminant Validity was verified through the values of the Heterotrait-Monotrait ratio (HTMT). All the values
Table 3 Indicator reliability, internal consistency and convergent validity of measurement model

\begin{tabular}{|c|c|c|c|c|c|c|}
\hline Constructs & Items & Outer Loadings & Cronbach Alpha & rho Alpha & $\mathrm{CR}$ & AVE \\
\hline \multirow[t]{3}{*}{ ADF } & ADF1 & 0.95 & \multirow[t]{3}{*}{0.926} & \multirow[t]{3}{*}{0.938} & \multirow[t]{3}{*}{0.953} & \multirow[t]{3}{*}{0.871} \\
\hline & ADF2 & 0.92 & & & & \\
\hline & ADF3 & 0.93 & & & & \\
\hline \multirow[t]{3}{*}{ CONV } & Conv1 & 0.91 & \multirow[t]{3}{*}{0.905} & \multirow[t]{3}{*}{0.908} & \multirow[t]{3}{*}{0.94} & \multirow[t]{3}{*}{0.84} \\
\hline & Conv2 & 0.93 & & & & \\
\hline & Conv3 & 0.91 & & & & \\
\hline \multirow[t]{3}{*}{ EB } & EB1 & 0.93 & \multirow[t]{3}{*}{0.863} & \multirow[t]{3}{*}{0.868} & \multirow[t]{3}{*}{0.917} & \multirow[t]{3}{*}{0.787} \\
\hline & EB2 & 0.83 & & & & \\
\hline & EB3 & 0.90 & & & & \\
\hline \multirow[t]{3}{*}{ ST } & ST1 & 0.90 & \multirow[t]{3}{*}{0.872} & \multirow[t]{3}{*}{0.888} & \multirow[t]{3}{*}{0.921} & \multirow[t]{3}{*}{0.795} \\
\hline & ST2 & 0.89 & & & & \\
\hline & ST3 & 0.89 & & & & \\
\hline \multirow[t]{4}{*}{ PB } & PB1 & 0.90 & \multirow[t]{4}{*}{0.869} & \multirow[t]{4}{*}{0.879} & \multirow[t]{4}{*}{0.91} & \multirow[t]{4}{*}{0.718} \\
\hline & PB2 & 0.81 & & & & \\
\hline & PB3 & 0.86 & & & & \\
\hline & PB4 & 0.82 & & & & \\
\hline \multirow[t]{3}{*}{ FR } & FR1 & 0.91 & \multirow[t]{3}{*}{0.903} & \multirow[t]{3}{*}{0.906} & \multirow[t]{3}{*}{0.939} & \multirow[t]{3}{*}{0.837} \\
\hline & FR2 & 0.90 & & & & \\
\hline & FR3 & 0.93 & & & & \\
\hline \multirow[t]{3}{*}{ SR } & SR1 & 0.94 & 0.909 & 0.909 & 0.943 & 0.847 \\
\hline & SR2 & 0.90 & & & & \\
\hline & SR3 & 0.93 & & & & \\
\hline PERF R & PERFR1 & 0.88 & 0.876 & 0.911 & 0.923 & 0.799 \\
\hline & PERFR2 & 0.91 & & & & \\
\hline & PERFR3 & 0.90 & & & & \\
\hline PR & PR1 & 0.92 & 0.901 & 0.901 & 0.938 & 0.835 \\
\hline & PR2 & 0.89 & & & & \\
\hline & PR3 & 0.94 & & & & \\
\hline
\end{tabular}


Table 4 Discriminant validity

\begin{tabular}{lrrrrrrrrr}
\hline & \multicolumn{1}{l}{ ADF } & \multicolumn{1}{l}{ Conv } & \multicolumn{1}{l}{ EB } & FR & PB & PR & Perf R & SR & ST \\
\hline ADF & 0.93 & & & & & & & & \\
Conv & 0.57 & 0.92 & & & & & & & \\
EB & 0.48 & 0.6 & 0.89 & & & & & & \\
FR & -0.51 & -0.49 & -0.46 & 0.91 & & & & & \\
PB & 0.55 & 0.67 & 0.83 & -0.53 & 0.85 & & & & \\
PR & -0.48 & -0.53 & -0.49 & 0.63 & -0.55 & 0.91 & & & \\
Perf R & -0.33 & -0.44 & -0.46 & 0.72 & -0.53 & 0.71 & 0.89 & & \\
SR & -0.52 & -0.48 & -0.46 & 0.72 & -0.51 & 0.62 & 0.59 & 0.92 & \\
ST & 0.66 & 0.77 & 0.68 & 0.52 & 0.71 & -0.55 & -0.44 & -0.49 & 0.89 \\
\hline
\end{tabular}

Table 5 HTMT ratio

\begin{tabular}{llllllllll}
\hline & Conv & DF & EB & FR & PB & PR & PerfR & SR & ST \\
\hline Conv & & & & & & & & & \\
DF & 0.622 & & & & & & & \\
EB & 0.684 & 0.523 & & & & & & \\
FR & 0.543 & 0.554 & 0.512 & & & & & \\
PB & 0.746 & 0.586 & 0.756 & 0.582 & & & & \\
PR & 0.589 & 0.524 & 0.554 & 0.7 & 0.623 & & & \\
PerfR & 0.484 & 0.358 & 0.522 & 0.804 & 0.611 & 0.78 & & \\
SR & 0.527 & 0.558 & 0.521 & 0.79 & 0.561 & 0.683 & 0.649 & \\
ST & 0.76 & 0.731 & 0.768 & 0.58 & 0.796 & 0.613 & 0.485 & 0.54 \\
\hline
\end{tabular}

Table 6 Multicollinearity examination

\begin{tabular}{ll}
\hline Constructs & VIF values \\
\hline CONV & 2.710 \\
EB & 3.466 \\
FR & 2.989 \\
PB & 4.160 \\
PR & 2.565 \\
PERF & 2.773 \\
SR & 2.341 \\
ST & 3.214 \\
\hline
\end{tabular}

were found to be under the limit of 0.85 , as shown in Table 5 (Henseler et al. 2015).

\section{Structural model}

The structural model was assessed through collinearity examination, the significance of the structural model and coefficient of determination $\left(\mathrm{R}^{2}\right)$ (Cohen 1988). Variance Inflation Factors (VIF) was used to determine the multicollinearity among the constructs (Henseler et al. 2009; Hair et al. 2012). The values obtained for VIF through SPSSv25 with latent variable scores were below the value of 5 , as shown in Table 6. Therefore, it is ensured that there is an absence of multicollinearity (Hair et al. 2012). Since the values of collinearity were justified, we can say that the
Table 7 Hypothesis testing

\begin{tabular}{lclll}
\hline Hypothesis & $\begin{array}{l}\text { Path coeffi- } \\
\text { cients }\end{array}$ & T Statistics & $P$-value & Decision \\
\hline $\mathrm{Conv} \rightarrow \mathrm{PB}$ & 0.17 & 2.02 & 0.05 & Supported \\
$\mathrm{EB} \rightarrow \mathrm{PB}$ & 0.63 & 6.57 & 0.05 & Supported \\
$\mathrm{FR} \rightarrow \mathrm{PR}$ & 0.09 & 0.71 & 0.05 & Not Supported \\
$\mathrm{PB} \rightarrow \mathrm{ADF}$ & 0.4 & 3.90 & 0.05 & Supported \\
$\mathrm{PR} \rightarrow \mathrm{ADF}$ & -0.26 & 2.66 & 0.05 & Supported \\
$\mathrm{Perf} \mathrm{R} \rightarrow \mathrm{PR}$ & 0.49 & 4.00 & 0.05 & Supported \\
$\mathrm{SR} \rightarrow \mathrm{PR}$ & 0.27 & 2.21 & 0.05 & Supported \\
$\mathrm{ST} \rightarrow \mathrm{PB}$ & 0.15 & 1.23 & 0.05 & Not Supported \\
\hline
\end{tabular}

relationship between the constructs was significant. The test of significance of constructs in the model was done through PLS-SEM bootstrapping algorithm. Using the original cases, a random sample of 5000 cases was generated to test the significance of the relationship between the construct (Henseler et al. 2009; Hair et al. 2012). The results are shown in Table 7. Figures 1, 2 displays the hypothesis testing. Post hypothesis testing, the calculation of the coefficient of determination $\left(\mathrm{R}^{2}\right)$ was done and was found to be satisfactory (Cohen 1988) and has been recorded in Table 8.

The model was also examined for good fit using standardized root mean square residual (SRMR), Normed fit index (NFI) and RMS theta. The SRMR value has been 
Fig. 1 Research model

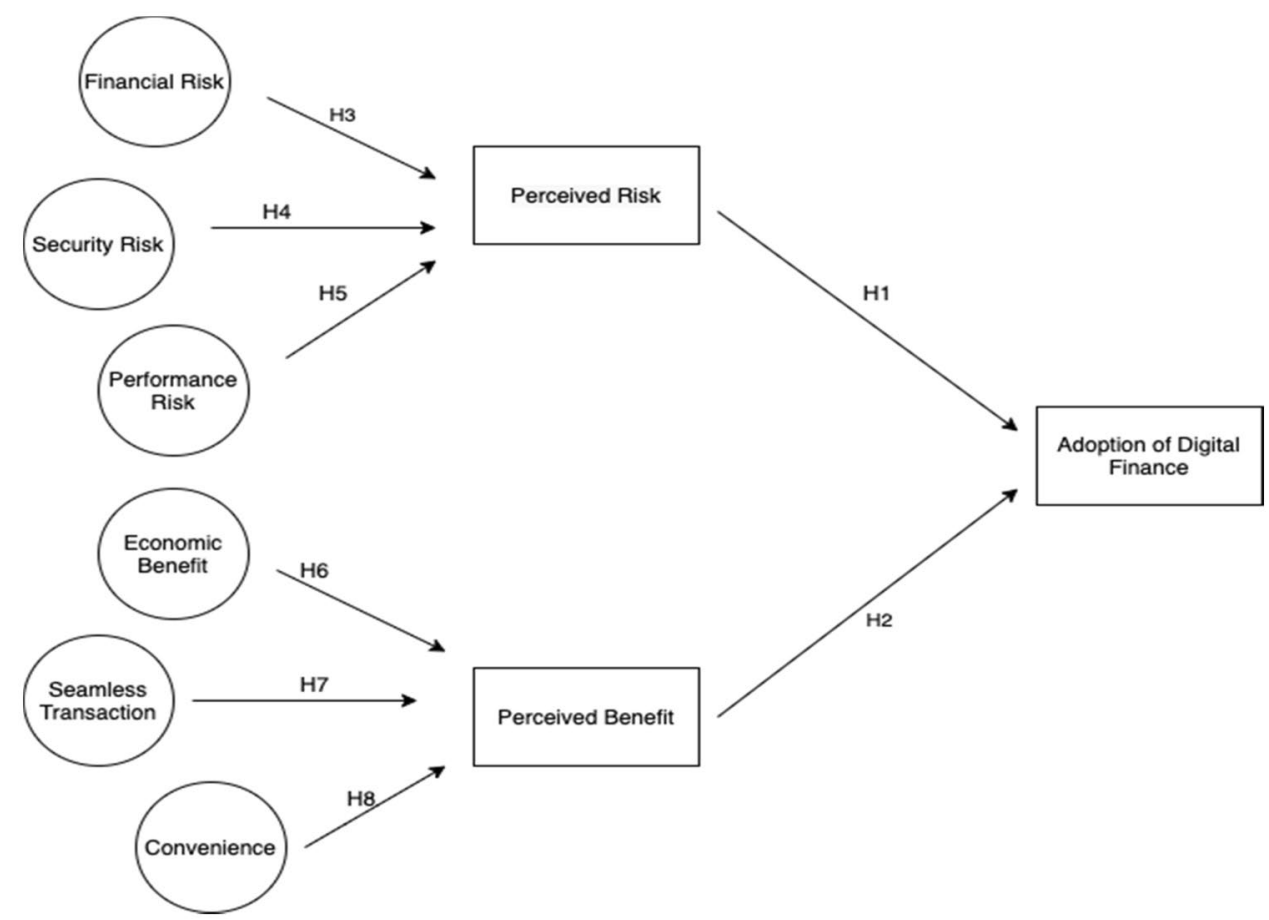

Fig. 2 Path coefficients and structural model

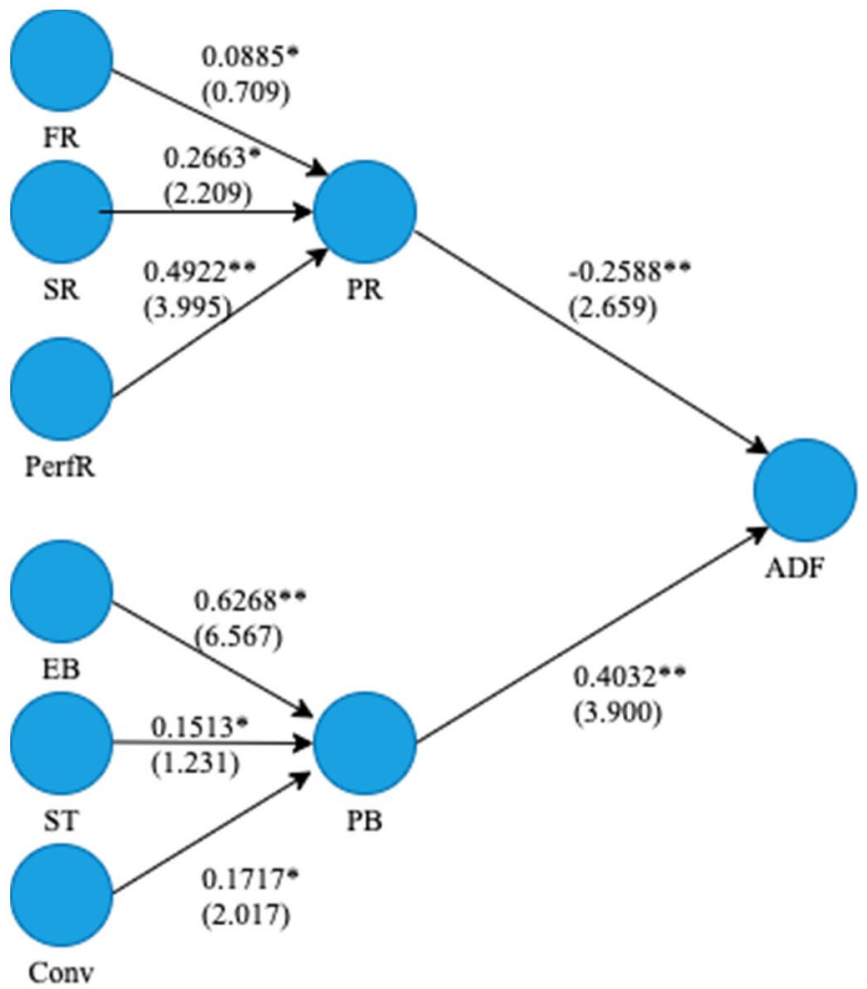

Note: ${ }^{*} \mathrm{p}<0.05,{ }^{* *} \mathrm{p}<0.01$

prescribed to be below the critical threshold limit of 0.08 (Henseler, et al., 2014; Hair et al., 2020). The value found was 0.073 , which indicates that the model is a good fit. NFI has been reported at 0.844 and RMS theta at 0.133 . 
Table $8 \mathrm{R}^{2}$ value

\begin{tabular}{ll}
\hline Variables & $\begin{array}{l}\text { Coefficient of } \\
\text { Determination } \\
\left(\mathrm{R}^{2}\right)\end{array}$ \\
\hline $\mathrm{PB}$ & 0.74 \\
$\mathrm{PR}$ & 0.57 \\
$\mathrm{ADF}$ & 0.35 \\
\hline
\end{tabular}

\section{Discussion and implications}

\section{Discussion}

PLS-SEM bootstrap algorithm was used to analyze the relationship among the constructs. The results showed that perceived risk had a negative impact on the adoption of digital finance and that perceived benefit had a positive impact on the adoption of digital finance. Therefore, $\mathrm{H}_{1}(\mathrm{t}=2.66$, $P<0.05)$ and $\mathrm{H}_{2}(\mathrm{t}=3.90, P<0.05)$ were supported. The results also concluded that perceived benefit had more influence on the adoption of digital finance than perceived risk. Therefore, respondents are willing to adopt digital finance. The perceived risk was further examined with the help of three variables which are- financial risk, performance risk and security risk. The study concluded that respondents find digital finance risky in terms of performance and security as it had a positive impact on perceived risk. Therefore, $\mathrm{H}_{4}$ $(\mathrm{t}=2.21, P<0.05)$ and $\mathrm{H}_{5}(\mathrm{t}=4.00, P<0.05)$ were supported. Whereas respondents did not confirm the association of financial risk with perceived risk. Hence, $\mathrm{H}_{3}(\mathrm{t}=0.71$, $P>0.05)$ was not supported. Variance in perceived risk was $57 \%$ explained by performance risk, security risk and financial risk.

Further, the results concluded that convenience and economic benefits positively impacted perceived benefits, which means that respondents found digital finance convenient and economically beneficial. So the study supported $\mathrm{H}_{6}(\mathrm{t}=6.57, P<0.05)$ and $\mathrm{H}_{8}(\mathrm{t}=2.02, P<0.05)$. The respondents did not associate the seamless transaction with perceived benefit, which signified that respondents did not see seamless transactions as a benefit associated with digital finance. Therefore, $\mathrm{H}_{7}(\mathrm{t}=1.23, P>0.05)$ was not supported. The summary of hypotheses testing are displayed in Table 9. The total variance in perceived benefit was $74 \%$, explained by convenience, seamless transaction and economic benefit (Table 10).

The research confirms the role of security and performance risk in perceived risk. Economic benefit and convenience contribute towards perceived benefit. Therefore, the study concluded that perceived risk and benefits play a major role in adopting Digital Finance. The weak association between financial risk and perceived risk contradicts the result of (Liu et al. 2012; Luo et al. 2010; Abramova and Böhme 2016). The strong association of economic benefit with perceived benefits is in accordance with the results of Gerlach et al. (2019). Perceived risks and benefits contributed to $35 \%$ of the variance in the adoption of digital finance. The findings of the study are in accordance with (Liu et al. 2012; Abramova and Böhme 2016; Lee 2009; Ryu 2018), which established the role of perceived risk and benefits experienced by people in terms of adoption of technology.

\section{Theoretical implications}

The present study provides insights into how the risks and benefits affect the adoption of digital finance among

Table 10 IPMA table

\begin{tabular}{lll}
\hline Constructs & Importance & Performances \\
\hline Conv & 0.069 & 56.853 \\
EB & 0.253 & 52.07 \\
FR & 0.023 & 46.003 \\
PB & 0.403 & 52.943 \\
PR & 0.259 & 47.67 \\
PerfR & 0.127 & 49.955 \\
SR & 0.069 & 44.74 \\
ST & 0.061 & 56.475 \\
Mean & 0.158 & 50.839 \\
\hline
\end{tabular}

Table 9 Summary of hypothesis testing

\begin{tabular}{ll}
\hline Hypotheses & Decision \\
\hline $\mathrm{H}_{1}:$ Perceived Risk negatively influences Digital Finance adoption & Accepted \\
$\mathrm{H}_{2}$ : Perceived Benefit positively influences Digital Finance adoption & Accepted \\
$\mathrm{H}_{3}$ : Financial risk is associated with perceived risk & Not Accepted \\
$\mathrm{H}_{4}:$ Security risk is associated with perceived risk & Accepted \\
$\mathrm{H}_{5}:$ Performance risk is associated with perceived risk & Accepted \\
$\mathrm{H}_{6}:$ Economic benefit is associated with perceived benefit & Accepted \\
$\mathrm{H}_{7}:$ Seamless transaction is associated with perceived benefit & Not Accepted \\
$\mathrm{H}_{8}:$ Convenience is associated with perceived benefit & Accepted \\
\hline
\end{tabular}


individuals. The study contributes to the existing literature in the following ways. First, the study considers both benefits and risk to evaluate a comprehensive perception of individuals in the adoption of digital finance. Second, the study has been undertaken after the early stage of the covid-19 pandemic. Since the perception of individuals has changed after the health crisis, the impact has remotely been observed in the responses of the individuals, which makes the study different from the previous studies conducted. Third, the study incorporated multidimensional aspects of perceived risk and benefits. It helps in better decision making by the individuals since both the negatives and positive features have been included.

\section{Practical implications}

Importance Performance Map Analysis (IPMA) was performed to examine the importance and performance of the variables on digital finance adoption as the target variable. By explaining the endogenous target construct's variation, the IPMA results show which exogenous variable's total effects are essential (Hair et al., 2018; Ringle and Sarstedt 2016). The results have been displayed in Fig. 3 and Table 9. The results suggest that perceived benefit and economic benefit are of great importance since both the importance and performance of both the variables are high, and thus, are important in explaining digital finance adoption behaviour. Further, the main focus should be on perceived risk as it is a performing variable but is not given enough performance and therefore needs to be proved. Seamless transaction, convenience and performance risk have a smaller total effect on digital finance adoption and realize moderate performance. Financial risk and security risk have both weak total effects and performance.

On the basis of IPMA results, we recommend that the strategists and policymakers keep on improving the perceived benefits associated with digital finance services. They should provide more factual information on the performance of digital financial services so that consumers have more knowledge of the same. This, in turn, will encourage them to develop a positive perception of digital financial services. As the results suggest, perceived risk plays an important role in the adoption behaviour of digital finance, which should be addressed by the financial service providers so that they can expand their customer base. The marketers should focus on advertising the benefits of digital financial services, especially economic benefits, since it is of great importance and have high performance. Further, wore emphasis and value given to the advertisement of advantages will, in turn, help to establish a significant impact of seamless transaction and convenience. In addition to advertisements, face to face interactions with the customers can also help in reducing their risk perception and hesitation as their concerns will be addressed. The promotion of the adoption of digital financial services can help in eradicating fake currency from the economy. It will also help to move towards the goal of financial inclusion. Society can gain from the transparency of the system and have complete trust in digital financial services.

Fig. 3 IPMA

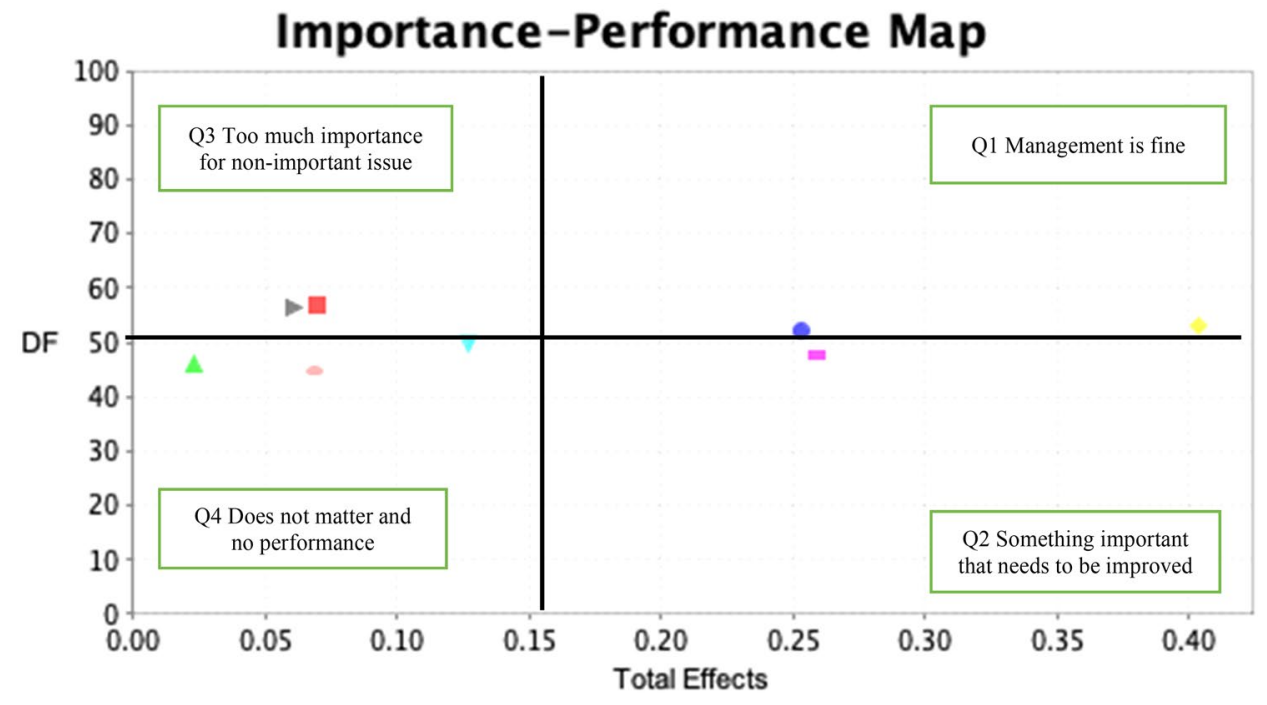

- Conv $\bullet \mathrm{EB} \triangle \mathrm{FR} \quad \mathrm{PB}=\mathrm{PR} \nabla \mathrm{PerfR}-\mathrm{SR} \nabla \mathrm{ST}$ 


\section{Conclusion}

In this ever-changing environment, information technology in finance is the need for the industry to grow in India. Crucial to the growth of the country, it is pertinent that people use digital finance as it not only helps in easy access to financial records but also helps in reducing the circulation of fake money, contributing to the gross domestic product of the country. Even though people are aware of the available financial services via digital platforms, yet they resist due to some risks or hesitations involved in the adoption of the technology. This study focussed on analyzing both aspects of technology adoption, i.e., perceived risks and benefits. Though, there is still some resistance from people, which should be overcome by the industry so that the adoption rate increases and people trust the process completely.

The study revealed that perceived benefits outweighs the perceived risk in adopting digital finance. This signifies that people are moving towards the adoption of digital finance. The study categorized perceived risk into financial risk, performance risk and security risk; perceived benefits into convenience, economic benefit and seamless transaction for a better understanding of how the users perceive digital finance. Through this study, an individual will have a better understanding of various risks and benefits associated with adopting technology and will be able to access their stand on digital finance.

It is empirical for the fintech industry to understand and work on a risk-free transaction environment in order to sustain and grow in the Indian economy. Therefore, they should work on strategies that would reduce the risks of using digital finance and improve confidence and influence potential users to adopt the technology. The study also gives an insight for financial managers marketing digital finance on which factors to be enhanced or avoided while promoting digital finance to potential users. This will also help the managers efficiently allocate their resources like time, effort and money so that they can improve their services and increase their existing customer base. The companies providing digital finance services should work on reducing risks and make the environment of digital finance stabilized and user friendly for users. The digital finance service providers should understand the target consumers and their concerns while designing new products and services that will cater to their needs and overcome the risks and enhance benefits received from digital finance services.

The present study can be used as a basis for further research in Digital Finance. As the study focussed on specific benefits and risks, other factors can be put into play in order to have a better understanding of individuals behaviour for the adoption of digital finance.
Limitations and future scope of the study

A significant contribution has been made through the present study, yet the study has some limitations which provide a future scope of research. First, the study addressed a limited set of perceived risk and benefits in the study restraining the literature review. Future studies can include more variables according to the circumstances in the economy. Second, the present study has not included the impact of gender or age on the adoption of digital finance, which can be explored in future studies. Third, as suggested, Covid-19 has played a significant role in expanding digital finance adoption through literature. Therefore, Covid19 can also be explored as a moderating variable in the studies to quantify the results. Another avenue that can be explored is examining the financially excluded individuals perception of the adoption of digital finance. Finally, the study discussed only the behaviour of individuals, whereas actual usage can also be examined.

Supplementary Information The online version contains supplementary material available at https://doi.org/10.1057/s41264-021-00127-8.

\section{References}

Abramova, S., and R. Böhme. 2016. Perceived benefit and risk as multidimensional determinants of Bitcoin use: A quantitative exploratory study. Proceedings in International Conference on Information Systems 2016: 1-20.

Agarwal, P., Chatterjee, S., \& Agarwal, P. 2017. Digital financial inclusion and consumer capabilities in India. Institute for Financial Management and Research.

Agur, I., Peria, S., \& Rochon, C. 2020. Digital financial services and the pandemic: Opportunities and risks for emerging and developing economies. IMF Research.

Aisaiti, G., L. Liu, J. Xie, and J. Yang. 2019. An empirical analysis of rural farmers' financing intention of inclusive finance in China: The moderating role of digital finance and social enterprise embeddedness. Industrial Management and Data Systems 119(7): 1535-1563.

Ajzen, I., and M. Fishbein. 1977. Attitude-behavior relations: A theoretical analysis and review of empirical research. Psychological Bulletin 84(5): 10236.

Alalwan, A.A., Y.K. Dwivedi, N.P. Rana, and R. Algharabat. 2018. Examining factors influencing Jordanian customers' intentions and adoption of internet banking: Extending UTAUT2 with risk. Journal of Retailing and Consumer Services 40: 125-138.

Alhakami, A.S., and P. Slovic. 1994. A psychological study of the inverse relationship between perceived risk and perceived benefit. Risk Analysis 14: 103.

Arner, D., J. Barberis, and R. Buckley. 2016. The evolution of fintech: A new post-crisis paradigm? Georgetown Journal of International Law 47(4): 1029.

Arner, D., Barberis, J., Walker, J., Buckley, R., Dahdal, A., \& Zetzsche, D. 2020. Digital Finance \& the Covid-19 crisis. 
Bagozzi, R.P., and Y. Yi. 1988. On the evaluation of structural equation models. Journal of the Academy of Marketing Science 16(1): 74-94.

Bank, E. 2001. E-Finance: The electronic revolution, 1st ed. Chichester: Wiley.

Bauer, R. 1967. Consumer behavior as risk taking. Risk Taking and Information Handling in Consumer Behavior. 2: 1036.

Barclay, D., C. Higgins, and R. Thompson. 1995. The partial least squares (PLS) approach to causal modelling: Personal computer adoption and use as an illustration. Technology Studies 2(2): 285-309.

Benlian, A., and T. Hess. 2011. Opportunities and risks of softwareas-a-service: Findings from a survey of IT executives. Decision Support Systems 52(1): 232-246.

Bergek, A., S. Jacobsson, S. Lindmark, B. Carlsson, and A. Rickne. 2008. Analyzing the functional dynamics of technological innovation systems. A Scheme of Analysis Research Policy 37(3): 407-429.

Buckley, R., D. Arner, D. Zetzsche, and E. Selga. 2020. TechRisk. Singapore Journal of Legal Studies. 12: 10369.

Cain, M., Z. Zhang, and K. Yuan. 2017. Univariate and multivariate skewness and kurtosis for measuring nonnormality: Prevalence, influence and estimation. Behaviour. Research Methods 9(3): 256-269.

CGAP. 2015. What is Digital Financial Inclusion and Why Does it Matter?

Chandon, P., B. Wansink, and G. Laurent. 2000. A benefit congruency framework of sales promotion effectiveness. Journal of Marketing 64: 65-81.

Cheng, T., D. Lam, and A. Yeung. 2006. Adoption of internet banking: An empirical study in Hong Kong. Decision Support Systems 42(3): 1558-1572.

Chin, W.W. 1998. Commentary: Issues and opinion on structural equation modelling. MIS Quarterly 22(1): vii-xvi.

Chishti, S. 2016. How peer to peer lending and crowdfunding drive the FinTech revolution in the UK. Banking Beyond Banks and Money 10: 55-68.

Cohen, J. 1988. Statistical Power Analysis for the Behavioral Sciences. Lawrence Erlbaum Associates.

Coltman, T., T.M. Devinney, D.F. Midgley, and S. Veniak. 2008. Formative versus reflective measurement models: Two applications of formative measurement. Journal of Business Research 61(12): 1250-1262.

Cunningham, S.M. 1967. The major dimensions of perceived risk. Risk Taking and Information Handling in Consumer Behavior 1: 82-111.

Farivar, S., \& Yuan, Y. 2014. The dual perspective of social commerce adoption. Proceeding in SIGHCI, (pp. 1-6).

Faul, F., E. Erdfelder, A. Buchner, and A. Lang. 2009. Statistical power analyses using $G^{*}$ power 3.1: tests for correlation and regression analyses. Behavior Research Methods 41(4): $1149-1160$

Featherman, M.S., and P.A. Pavlou. 2003. Predicting e-services adoption: A perceived risk facets perspective. International Journal of Human Computer Studies 2: 451-474.

Fernando, E. 2019. The influence of perceived risk and trust in adoption of FinTech services in Indonesia. Communication and Information Technology Journal 13(1): 10369.

Finau, G., N. Rika, J. Samuwai, and J. McGoon. 2016. Perceptions of digital financial services in Rural Fiji. Information Technologies \& International Development 12(4): 11-21.

Fornell, C., and D. Larcker. 1981. Evaluating structural equation models with unobservable variables and measurement error. Journal of Marketing Research 18(1): 39-50.
Forsythe, S., C. Liu, D. Shannon, and L.C. Gardner. 2006. Development of a scale to measure the perceived benefits and risks of online shopping. Journal of Interactive Marketing 20: 55-75.

Frakman, M. 2020. India's digital financial services opportunity in a Post-COVID world. Retrieved from ORF Research: https://www. orfonline.org/expert-speak/indias-digital-financial-services-oppor tunity-in-a-post-covid-world-67832/

Fu, J., and M. Mishra. 2020. The global impact of COVID-19 on fintech adoption. Swiss Finance Institute 2: 20-38.

$\mathrm{Fu}, \mathrm{X}$. 2014. Diffusion of Innovation in Low Income Countries. UNCTAD: Oxford University.

Gerlach, J.M., H.-H.U. Duesseldorf, and J.K.T. Lutz. 2019. Evidence on usage behavior and future adoption intention of fintech and digital finance solutions. The International Journal of Business and Finance Research 13(2): 83-105.

Gomber, P., J.A. Koch, and M. Siering. 2017. Digital finance and FinTech: Current research and future research directions. Journal of Business Economics 87(5): 537-580.

Hair, J., H. Matthew, and N. Christian. 2020. Assessing measurement model quality in PLS-SEM using confirmatory composite analysis. Journal of Business Research 109: 101-110.

Hair, J.F., C.M. Ringle, and M. Sarstedt. 2011. PLS-SEM: Indeed a silver bullet. The Journal of Marketing Theory and Practice 19(2): 139-152.

Hair, J., J. Risher, M. Sarstedt, and C. Ringle. 2019. When to use and how to report the results of PLS-SEM. European Business Review 31(1): 2-24.

Hair, J.F., M. Sarstedt, T.M. Pieper, and C.M. Rigle. 2012. The use of partial least squares structural equation modelling in strategic management research: A review of past practices and recommendations for future applications. Long Range Planning 45 (5-6): 320-340.

Hair, J., Sarstedt, M., Ringle, C., \& Gudergan, S. 2018. Advanced Issues in Partial Least Squares Structural Equation Modeling. CA: Thousand Oaks.

Henseler, J., T. Dijkstra, M. Sarstedt, C. Ringle, A. Diamantopoulos, D. Straub, and R. Calantone. 2014. Common beliefs and reality about partial least squares: Comments on Rönkkö and Evermann 2013. Organizational Research Methods 17 (2): 182-209.

Henseler, J., C. Ringle, and M. Sarstedt. 2015. A new criterion for assessing discriminant validity in variance-based structural equation modeling. Journal of the Academy of Marketing Science 43: 115-135.

Henseler, J., Ringle, C. M., \& Sinkovics, R. R. 2009. The use of partial least squares path modeling in international marketing", in Sinkovics, R.R. and Ghauri, P.N. (Eds). New Challenges to International Marketing (Advances in International Marketing, 20, 277-319.

Im, I., Y. Kim, and H.J. Han. 2008. The effects of perceived risk and technology type on users' acceptance of technologies. Information and Management 45(1): 1-9.

Jurison, J. 1995. The role of risk and return in information technology outsourcing decisions. Journal of Information Technology 10(4): 239.

Kim, C., M. Mirusmonov, and I. Lee. 2010. An empirical examination of factors influencing the intention to use mobile payment. Computers in Human Behavior 26(3): 310-322.

Kim, D., D. Ferrin, and H. Rao. 2008. A trust-based consumer decision-making model in electronic commerce: The role of trust, perceived risk, and their antecedents. Decision Support Systems 44(2): 544-564.

Königsheim, C., M. Lukas, and M. Nöth. 2017. Financial knowledge, risk preferences, and the demand for digital financial services. Schmalenbach Bus Rev. 2: 1739. 
Kuisma, T., T. Laukkanen, and M. Hiltunen. 2007. Mapping the reasons for resistance to internet banking: a means-end approach. Internation Journal inform Manage 27: 10236.

Lee, M.C. 2009. Factors influencing the adoption of internet banking: An integration of TAM and TPB with perceived risk and perceived benefit. Electronic Commerce Research and Applications 8: $130-141$.

Li, J., Y. Wu, and J.J. Xiao. 2019. The impact of digital finance on household consumption: Evidence from China. Economic Modelling. 12: 1039.

Liu, Y., Yang, Y., \& Li, H. 2012. A Unified risk-benefit analysis framework for investigating mobile payment adoption. Proceedings in International Conference on Mobile Business 2012.

Luo, X., H. Li, J. Zhang, and J.P. Shim. 2010. Examining multidimensional trust and multi- faceted risk in initial acceptance of emerging technologies: An empirical study of mobile banking services. Decision Support Systems 49(2): 222-234.

Lwin, M., J. Wirtz, and J. Williams. 2007. Consumer online privacy concerns and responses: A power-responsibility equilibrium perspective. Journal of the Academy of Marketing Science 35(4): 572-585.

Mackenzie, A. 2015. The fintech revolution. London Business School Review 26(3): 50-53.

Manyika, J., Lund, S., Singer, M., White, O., \& Berry, C. 2016. Digital finance for All: Powering Inclusive Growth in Emerging Economies. Mckinsey Global Institute.

Mardia, K. 1970. Measures of multivariate skewness and kurtosis with applications. Biometrika 57(3): 519-530.

Martins, C., T. Oliveira, and A. Popovič. 2014. Understanding the internet banking adoption: A unified theory of acceptance and use of technology and perceived risk application. International Journal of Information Management 34(1): 1-13.

Melewar, T., S. Alwi, M.T. Liu, J. Brock, G.C. Shi, R. Chu, and T. Tseng. 2013. Perceived benefits, perceived risk, and trust: Influences on consumers' group buying behaviour. Asia Pacific Journal of Marketing and Logistics 25(2): 225-248.

Meyliana, Fernando, E., \& Surjandy. 2019. The Influence of Perceived Risk and Trust in Adoption of FinTech Services in Indonesia. CommIT (Communication \& Information Technology) Journal, 31-37.

Nunnally, J. C., \& Bernstein, I. H. 1994. Psychometric Theory, 3rd ed.

Nutty, D.D. 2008. The adequacy of response rates to online and paper surveys: What can be done? Assessment and Evaluation in Higher Education 33(3): 301-314.

Okazaki, S., and F. Mendez. 2013. Exploring convenience in mobile commerce: Moderating effects of gender. Computers in Human Behavior 29(3): 1234-1242.

Ozili, P. K. 2018. Impact of Digital Finance on Financial Inclusion and Stability. Borsa Istanbul Review.

Peter, J., and L. Tarpey. 1975. A comparative analysis of three consumer decision strategies. Journal of Consumer Research 2(1): 29-37.
Podsakoff, P.M., S.B. MacKenzie, J.Y. Lee, and N.P. Podsakoff. 2003. Common method biases in behavioral research: A critical review of the literature and recommended remedies. The Journal of Applied Psychology 88(5): 879-903.

Razzaque, A., R.T. Cummings, M. Karolak, and A. Hamdan. 2020. The Propensity to Use FinTech: Input from Bankers in the Kingdom of Bahrain. Journal of Information \& Knowledge Management 19(1): 1039.

Reinartz, W., M. Haenlein, and J. Henseler. 2009. An empirical comparison of the efficacy of covariance-based and variance-based SEM. International Journal of Research in Marketing 26(4): 332-344.

Ringle, C., and M. Sarstedt. 2016. Gain more insight from your PLSSEM results the importance-performance map analysis. Industrial Management Data System 116: 1865-1886.

Robson, C., and K. McCartan. 2016. Real World Research. Hoboken: Wiley.

Ryu, H. S. 2018. What makes users willing or hesitant to use Fintech?: The moderating effect of user type. Industrial Management \& Data Systems.

Safeena, R., H. Date, and A. Kammani. 2011. Internet banking adoption in an emerging economy: Indian Consumer's perspective. International Arab Journal of e-Technology 2(1): 102369.

Staats, H. 2004. Pro-environmental attitudes and behavioral change. In Encyclopedia of Applied Psychology (pp. 127-135).

Thomas, H., \& Hedrick-Wong, Y. 2019. How digital finance and fintech can improve financial inclusion. In Inclusive Growth, 27-41.

Tiong, W. 2020. Factors influencing behavioural intention towards adoption of digital banking services in Malaysia. International Journal of Asian Social Science 10(8): 450-457.

Wilkie, W., and E. Pessemier. 1973. Issues in marketing's use of multiattribute attitude models. Journal of Marketing Research 10(4): 428-441.

Wong, B.Y.M., T.H. Lam, A.Y.K. Lai, M.P. Wang, and S.Y. Ho. 2021. Perceived benefits and harms of the covid-19 pandemic on family well-being and their sociodemographic disparities in Hong Kong: A cross-sectional study. International Journal of Environmental Research and Public Health 18(3): 1-14.

Yang, Q., Pang, C., Liu, Yen, D. C., \& Tarn, M. 2015. Exploring consumer perceived risk and trust for online payments: An empirical study in China's younger generation. Computers in Human Behavior, 9-24

Zhao, Y., and F. Bacao. 2021. How does the pandemic facilitate mobile payment? An investigation on users' perspective under the COVID-19 pandemic. International Journal of Environmental Research and Public Health 18(3): 1-22.

Publisher's Note Springer Nature remains neutral with regard to jurisdictional claims in published maps and institutional affiliations. 